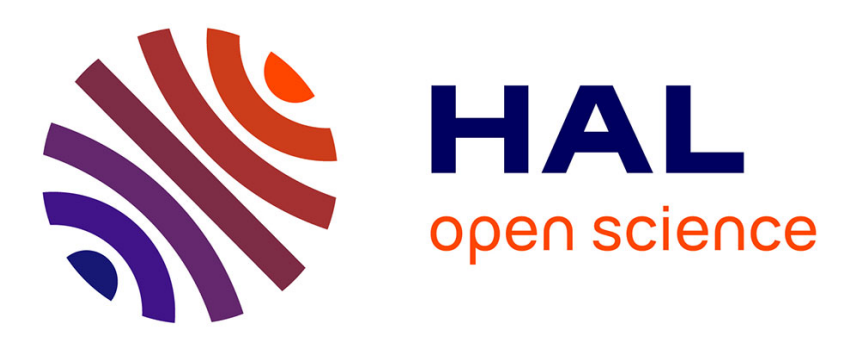

\title{
Natural Disasters and Countries' Exports: New Insights from a New (and an Old) Database
}

\author{
Hajare El Hadri, Daniel Mirza, Isabelle Rabaud
}

\section{To cite this version:}

Hajare El Hadri, Daniel Mirza, Isabelle Rabaud. Natural Disasters and Countries' Exports: New Insights from a New (and an Old) Database. The World Economy, 2019, 42 (9), pp.2668-2683. 10.1111/twec.12833 . hal-02411650

\section{HAL Id: hal-02411650 \\ https://hal.science/hal-02411650}

Submitted on 15 Dec 2019

HAL is a multi-disciplinary open access archive for the deposit and dissemination of scientific research documents, whether they are published or not. The documents may come from teaching and research institutions in France or abroad, or from public or private research centers.
L'archive ouverte pluridisciplinaire HAL, est destinée au dépôt et à la diffusion de documents scientifiques de niveau recherche, publiés ou non, émanant des établissements d'enseignement et de recherche français ou étrangers, des laboratoires publics ou privés. 


\title{
Natural Disasters and Countries' Exports: New Insights from a New (and an Old) Database
}

\author{
July 17, 2017
}

Hajare El Hadri ${ }^{a}$

${ }^{a}$ Univ. Orléans, CNRS, LEO, UMR 7322

Rue de Blois - BP 26739, 45067 Orléans Cedex 2, France

e-mail: hajare.el-hadri@univ-orleans.fr

Daniel Mirza ${ }^{b, c}$

${ }^{b}$ Univ. Tours, CNRS, LEO, UMR 7322 and ${ }^{c}$ CEPII (Paris)

Faculté de Droit, d'Economie et de Sciences Sociales

50 avenue Jean Portalis, 37200 Tours, France

e-mail: daniel.mirza@univ-tours.fr

Corresponding author

Isabelle Rabaud ${ }^{d}$

${ }^{d}$ Univ. Orléans, CNRS, LEO, UMR 7322

Rue de Blois - BP 26739, 45067 Orléans Cedex 2, France

e-mail: isabelle.rabaud@univ-orleans.fr

\begin{abstract}
This paper revisits the impact of disasters on exports while focusing on important disasters due to storms, floods, earthquakes and changes in temperatures, from 1979 to 2000. We mobilize two different datasets to add up robustness to our results: the EMDAT dataset, widely used in the literature; and GeoMet a newly available dataset based on geophysical and meteorological data(?). We run series of regressions while accounting progressively for the characteristics of products (all traded goods $\mathrm{v} / \mathrm{s}$ agriculture ones), the characteristics of the country (size, level of development) and the intensity of the catastrophes. When pooling all countries, and all types of disasters, we do not find any statistical impact on exports. But when focusing on each of them separately and on agricultural goods, the occurrence of an earthquake appears to reduce exports of about $3 \%$, regardless of its location. A windstorm shock, mainly when it happens to be very severe, is estimated to curb agricultural export flows by $7 \%$, but only in case of small countries. A flood, on its side, is estimated to reduce export flows of a poor country by around $1.78 \%$. The effect of changes in temperatures is ambiguous. All in all, except for temperatures related disasters, the results are consistent across both datasets, EM-DAT and GeoMet, although they appear to be slightly more in line with our expectations in the case of GeoMet.
\end{abstract}

Keywords: Natural Disasters, Trade, Environment, Agriculture

JEL codes: Q54, F18, Q17, F14 


\section{Introduction}

The number of catastrophic events increased dramatically since 1965, with an acceleration of their occurrence during the last fifteen years or so, where they have been multiplied by around 5 since the 1960s. In its Annual Disaster Review, the Center for Research on the Epidemiology of Disasters (?) reports for the period 2000-2015 an average of 350 natural disasters per year since the beginning of the years 2000s, with around 70,000 deaths per year, letting more than 15 to 20 millions persons injured or homeless per year and causing an average material cost of about $\$ 120$ billion. How are disasters shaping exports of victim countries? Do their effects on trade differ with respect to the types of disasters and their intensity? Do some sectoral and countries' characteristics matter?

Some research has been focusing on sectoral and macroeconomic outcomes of natural disasters. ? survey the literature devoted to the New Climate-Economy. Among the cited works, ?, ? and ? provide examples. To synthesize their findings, agricultural output appears to be one of the sectors that is most hit in the economy. Further, industrial output, energy demand, labor productivity, health, conflict and political stability happen to be affected, all of these ending-up curbing economic growth. Besides, small and poor countries, being often associated with poor quality of institutions and low education levels, appear to be much more sensitive to temperature shocks. Finally, the impact on outcomes is all the more significant in the presence of severe disasters.

Nevertheless, the literature on the induced impact on trade flows has been relatively scarce. ? had already highlighted the lack and need of studies on the link between trade and environmental related events. To the best of our knowledge, three papers deal with this aspect. ? look at the impact of temperatures and precipitations on sectoral exports to the US and the World respectively, by using a cross-country database from 1973 to 2001. They find that temperatures - albeit not precipitations - reduce exports of poor countries: a 1 celsius degree warmer happen to reduce their exports by 2 to 5.7 percentage points. Agriculture happens to be however, more affected than manufacturing. As for natural disasters, ? rely on a gravity model to estimate their impact on international trade for 116 countries over the period 1985 to 2003. They find an induced reduction of both imports and exports following disasters. Besides, the higher the political risk and the stronger this decrease. ? analyze the impact on trade of major natural and technological disasters. They rely on bilateral trade from 1962 to 2004 and use again a gravity equation à la Rose. In their first series of results, the impact of the number of disasters does not appear to be significant on bilateral imports. However the number of disasters adjusted for the surface of the country deters exports and imports. Besides, they find that the (negative) effect is stronger in autocratic and smaller countries.

Importantly for our paper, most of the studies use the Emergency Event Database (EMDAT) to analyze the impact of disasters on outcome variables. ${ }^{1}$ ? note however, that the

\footnotetext{
${ }^{1}$ Through their use of other data sources, ? and ? appear among few exceptions, however.
} 
EM-DAT database might not be suitable if one needs to exploit the data on the intensity of the disasters. The reason mentioned by these authors is that the intensity of disasters, usually measured from EM-DAT by the amount of damage or number of victims, is itself correlated with the level of development, which makes it difficult to use such measures as independent variables to explain variables such as GDP per capita but also migration or trade.

To avoid this caveat ? compile and use a new alternative database built on geophysical and meteorological measures (i.e GeoMet database) to examine the impact of disasters on growth. These measures could then offer the authors the possibility of assessing the link to growth, derived from the physical strength of the disasters, a measure not reported by EM-DAT. By doing so they could produce results that are quite different from the rest of the literature: they find indeed a strong negative and statistically significant effect of disasters on growth.

This paper is the first to uncover the impact of different families of disasters, while testing for the heterogeneity of their impact on exports. It does so by using the standard $E M-D A T$ data and GeoMet data. Our paper is mainly interested in the impact of disasters on trade through the supply of resources channel. We ask here, as in Jones and Olken, what is the impact of disasters on aggregate exports of a country when driven by a reduction in its resource capacities (labour capacities, crops, public infrastructure). A disruption of supply due to a disaster would affect a priori export flows across partners in the same fashion which is why we do not consider here gravity equations, the latter being better suited to explain trade across bilateral pairs of countries. That is why we use here the specification of ?.

We begin by comparing the impact of the measures of occurrence or number of death-type measures accessible via EM-DAT with a composite measure of physical intensity of disasters computed from GeoMet, encompassing the intensity of different types of disasters. When pooling all countries, all products and all types of disasters, we do not find any statistical impact on exports, whichever the database at hand (EM-DAT or GeoMet). Besides, a concentration on agricultural products specifically does not bring much to the picture. In a second phase, we focus on each type of disaster separately and interact each of these with the size and the level of development of the countries, two of the characteristics of the countries which are known to play a role in the expected influence of disasters on aggregate outcomes. There, earthquakes appear to have a general and statistically robust depressive impact on agricultural exports irrespective of the characteristics of the countries. Floods and storms to some extent, curb agricultural export flows but only for small countries in the case of the former and in poor countries for the latter. Changes in temperatures appear to affect exports of small and poor countries too, but only when GeoMet data are considered. We then ask, in final series of regressions, whether very strong disasters, observed in terms of number of deaths (from EM-DAT) or physical intensity (GeoMet), if taken apart, exhibit an additional impact on trade or whether alternatively, the effects observed previously are being mainly driven by those very severe disasters. We thus design by very severe (or extreme) disasters, all disasters that belong to the top $20 \%$ of the distribution in terms of number of geophysical and meteorological intensity on one hand and 
number of deaths on the other. There, we find that extreme disasters are likely to be those first responsible for trade reductions, but the effect differs again, with respect to its type and that of the countries observed: in particular, extreme floods reduce agricultural exports but only in the case of small countries. Extreme storms are also associated with a reduction in exports but only in poor countries. And again, the $20 \%$ of extreme temperatures affect exports but only when using physical intensity GeoMet data. Finally, extreme earthquakes appear to be hitting exports irrespective of their size or wealth. Interestingly however, except for the case of temperatures, all of the above cited results appear to be robust to the use of both types of datasets, EM-DAT and GeoMet. Hence, researchers working on the impact of disasters on trade might want to consider either of these in future research, although our preference goes to GeoMet as the results we obtain using the latter appear to be slightly more in line with our expectations.

The outline of the paper is the following. Section 2 presents the data and the methodology. Section 3 displays the impact of natural disaster on exports. We conclude in section 4 .

\section{Data}

In order to stay in line with the prior literature by enabling replication of results, and comparing its outcomes easily with our new results, we follow ?. Like these authors, we base our study on the NBER-United Nations countries' exports data, at the two digit level of disaggregation for all goods and agricultural products. To match with both databases on disasters, we reduce however our phase of observation to the period 1979-2000.

As for disasters, we use two databases: the Emergency Event Database (EM-DAT), delivered by the Center of Research on the Epidemiology of Disasters (CRED) at University of Louvain (?) and the Geophysical and Meteorological database (GeoMet), set by ? and based on five primary sources mainly used in geophysics or climatology.

We begin by presenting the catastrophes data that we extract from EM-DAT. The latter reports on technological and natural events. We focus here on the last one. For a disaster to be reported into the EM-DAT database at least one of the following criteria must be met: ten or more people reported killed, hundred or more people reported affected, a declaration of the state of emergency, and a call for international assistance. As we focus on changes in aggregate export figures due to disasters, we thought that only sufficiently important disasters should be considered in our study, those which should have a suitably important impact on resources for production and exports. We thus concentrate uniquely on "significant events", where the ratio of the number of deaths to total population is above the median of the distribution across all countries of the sample for a given year. ${ }^{2}$ We could then define two variables out of EM-DAT:

\footnotetext{
${ }^{2}$ We have also considered other criteria to select "significant events" based on ? with at least one of the criterium to be met: a minimum threshhold of 1,000 deaths; a minimum threshhold of 1,000 injured, and a
} 
on the one hand, a variable of number of occurrence of significant events for each country overtime and on the other hand, based on the number of deaths from these events, a variable of intensity of human damage.

Second, we turn to the Geophysical and Meteorological database (GeoMet), following the work of ?. The database here reports the physical magnitudes of each occurring disaster, which will be our alternative measure of intensity. We select 4 types of disasters directly comparable across the two databases and for which we have sufficient data for the period considered: earthquakes, extreme temperatures, flood and windstorms. ? measure the intensities related to each of the disasters at hand by applying the following measurement scales:

- Floods: the deviation of total monthly rainfalls from the average monthly rainfalls for the entire period (1979-2000),

- Extreme temperatures: the deviation of total monthly temperatures from the average monthly temperatures for the whole period (1979-2000),

- Earthquakes: the Richter scale in value for each earthquake observed,

- Windstorms: the wind speed in value for each storm observed.

From these monthly or event level observations, the authors then produce yearly aggregates at the country level, by selecting the corresponding maximum values observed each year and for each country. We replicate their method and also follow theses authors to build a composite physical intensity index as the sum of each of the previous physical intensity measures weighted by the inverse of their standard deviation. We call this additional variable Index.

\section{The impact of natural disasters on trade}

We extend the work of ? to analyze the effect of natural disasters experienced in a country on its level of total exports to the world. The former authors have already demonstrated that climate changes (variations in temperatures and precipitations) reduce exports. By analogy, one might expect other natural disasters to affect exports as they can be responsible for the destruction of factors of production (human, physical capital, crops, land, infrastructures) besides affecting water availability, which might curb production and exports.

We replicate the equation of ? on a shorter period 1979-2000, time for which we have the corresponding data in EM-DAT and GeoMet. Like ?, we apply Feasible Generalized Least Square (FGLS) to adjust for heteroskedasticity. The specification computed in log differences (which small variations capture export growth) is represented by what follows:

minimum amount of losses no less than 1 billion. We obtain quite similar results which can be shown upon request. 
$\ln \left(E X_{i t}^{k}\right)-\ln \left(E X_{i t-1}^{k}\right)=c_{i t}^{k}+\beta_{1}$ disaster $_{i t}+\beta_{2}$ disaster $_{i t} \times$ countrycharacter $\left._{i}+\lambda_{i}^{k}+\lambda_{t}^{k}+\epsilon_{t}^{k} 1\right)$

with, $\ln \left(E X_{i t}^{k}\right)$, the logarithm of exports of country $i$ for product $k$ in value at a given year $t$. Depending upon the different specifications, the variable disaster ${ }_{i t}$ can take the following expressions:

- $\ln \left(\right.$ occurrence $\left._{i t}+1\right)$, the logarithm of one plus the number of major disasters which occur in an exporting country $i$ at year $t$;

- $\ln \left(\right.$ deaths $\left._{i t}+1\right)$, the logarithm of one plus the number of persons reported to be killed in these major disasters ;

- index $_{i t}$, a composite index constructed exactly as in ?, for an exporting country $i$ at any given year $t$ and computed as the sum of the intensities of the four types of natural disasters weighted by the inverse of their standard deviation;

- $\ln \left(\right.$ flood $\left._{i t}+1\right), \ln \left(\right.$ storm $\left._{i t}+1\right), \ln \left(\right.$ earthquake $\left._{i t}+1\right)$ and extremetemp $p_{i t}$ the corresponding intensity of each type of disaster, respectively floods, storms, earthquakes and extreme temperatures for an exporting country $i$ at year $t$.

Besides, the interaction term disaster ${ }_{i t} \times$ countrycharacter $_{i}$ expresses the interaction between the chosen disaster variable and some of the characteristics of the country. ? consider one particular feature: the fact of observing or not a poor country. The observed country is considered to be poor if it is in the bottom half of the world per-capita purchasing power parity (PPP) of the world income distribution in 1995. We propose to replicate their specification by considering again this particular feature that a country could have. Nevertheless, we also replace it in alternative specifications by another feature: the size of the country. As some papers suggest, small countries might suffer more than big ones from disasters which give us another opportunity to test this claim by interacting alternatively with a small country term (where small is considered whenever the country's population is under 20 million inhabitants).

We also introduce $\lambda_{i}^{k}$ and $\lambda_{t}^{k}$. The exporter $\times$ product fixed effects $\lambda_{i}^{k}$ capture cross-country differences in growth of export for each product. The product $\times$ time fixed effects $\lambda_{t}^{k} \operatorname{control}$ for changes in world prices or world demand that could affect changes in exports for each product being observed. The $\epsilon_{i t}^{k}$ term represents the residual.

As in ?, we begin by pooling all 2 digits products, then in a second phase we concentrate on agricultural products only. Column 1 in table ?? is a straightforward replication of their regression, using their measures of extreme temperatures and precipitations, while using a slightly different period here. 


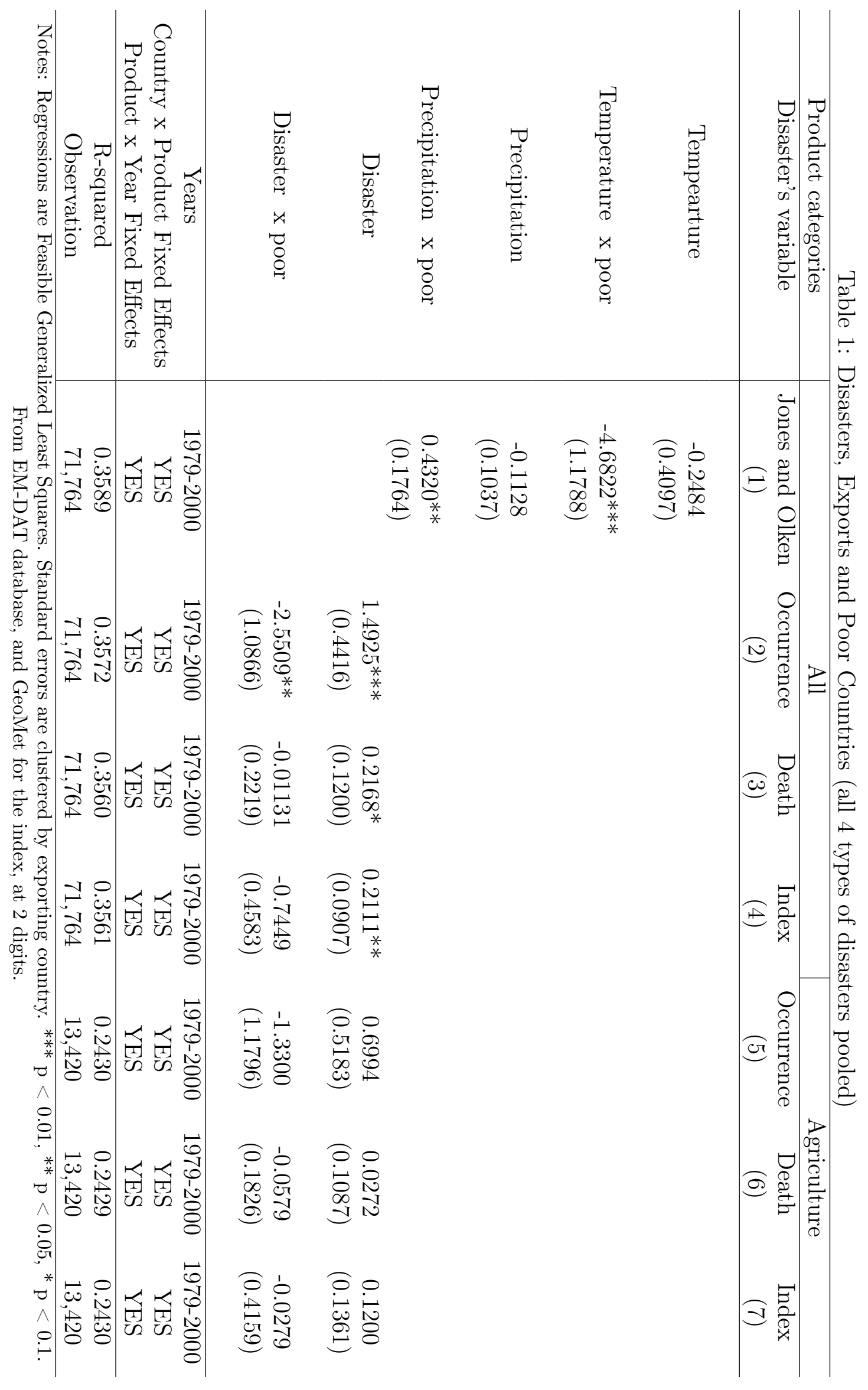


Our results replicate and thus confirm the findings of the authors: changes in temperature produce a negative and statistically significant effect on exports of poor countries. Nonetheless, as also found by these authors, we retrieve precipitations to appear with a surprising positive and statistically significant effect when the country considered is poor ${ }^{3}$. The rest of the countries do not seem to be affected by climate change variables.

Next, we apply the same model starting by using from now our measures of natural disasters, coming from EM-DAT and GeoMet. When all goods exported are considered (including agriculture and manufacturing), natural disasters come out to be positively (not negatively) associated with exports of non-poor countries. All the more, the sign and significance of the estimator for non-poor countries appears to be robust across our three specifications (occurrence, number of deaths and physical damage, see columns 2 to 4, in table 1). Turning to the interaction terms (disaster $\times$ poor), one should interpret here the related estimators for poor countries as deviations from the estimators on the disaster variable at the row just above. In fact, we find that the interaction estimator deviates negatively from the effect found for non-poor countries, in all 3 specifications, albeit it is negative, statistically significant and higher in absolute value than the estimator for non-poor countries, only in one case (i.e when the occurrence variable is considered). All in all, and when considering all goods exported, such results are actually surprising. They indicate that we might not be well capturing the expected negative impact of disasters (through their effect on supply of resources). Other factors are probably at stake. Also, GeoMet does not appear to bring a different result than EM-DAT in these specifications (when all types of disasters and all goods are pooled).

Nevertheless, by focusing only on agricultural products (see columns 5 to 7 , table 1 ), the statistical significance of the effects disappears whatever the variable considered across our two databases EM-DAT and GeoMet. These series of results tend to show, again, however, that pooling-up different types of disasters, even when one concentrates on agriculture and studies the specific impact for poor countries, does not enable to produce a robust negative effect of catastrophes on exports.

As noted, the expected negative effect of disasters does not seem to show up in a robust manner when assuming a priori homogeneity of the effects across all of these disasters. However, the four types of disasters might not be comparable, when looking at how they can affect the economy. Especially, for the physical intensity index obtained from GeoMet, one can hardly compare say the impact of one standard deviation increase in Richter scale of earthquakes with a standard deviation of rainfalls from the average tendency, because the scales themselves are not comparable across disasters. Besides, even for the human damage measure from EM-DAT,

\footnotetext{
${ }^{3}$ The authors show however, that this positive and statistically significant effect is not robust to slight changes in the data considered.
} 
it is very plausible say, that an earthquake producing 100 deaths might still be affecting crops and also transportation networks much more than, say, a storm that provokes the same number of deaths.

That is why we break down disasters by type in what follows. Further, insofar as the literature has shown that poor but also small countries were more affected by economic drawbacks of climate change and disasters, we introduce an interaction term between disasters and poor economies, on the one hand (table 2) and interactions with small nations, on the other hand (table 3).

Table 2 shows the first related results and indeed, results appear to be strikingly different across our four disasters. Hit countries' exports do not appear to be impacted by the occurrence of floods, neither by the intensity of human and physical damage to which they are related. Besides, poor countries are not more harmed than non-poor ones when floods are considered (see columns 1 to 3, table ??). Nevertheless, exports of hit countries decrease after earthquakes, how ever measured (occurrence, human damage, physical intensity). Again, no additional poor effect shows up (columns 7 to 9, table ??). Columns 10 to 12 tend to show that extreme temperatures appear to produce more negative effects for poor countries than for non poor ones, but statistical significance is observed only when the damage is expressed in physical terms (i.e GeoMet data are mobilized). Finally, from columns 4 to 6 , one can find that the occurrence and the intensities of storms tend to foster not deter exports but for non poor countries only. Poor countries are associated with a negative significant effect of windstorms on exports (see interaction term, disaster $\times$ poor), that is higher in absolute values than that on the disaster variable (row above), except when deaths are considered.

Table 3 introduces the size of the country as an alternative interaction variable. Here again, earthquakes still depress exports with robust statistical significance whichever the size of the country is (see columns 7 to 9 , table ??). Floods seem to affect negatively exports of small countries only (see statistical significance on interaction term, columns 1 to 3, table ??). The effect related to extreme temperatures, appears to be negative and statistically significant on exports of small countries but only when intensity is measured by GeoMet. No effect is observed however, for big countries (see columns 10 to 12, table ??). Finally, and at odds with what could be expected, the storms' related results cannot be well interpreted: while storms appear with a positive but non significant impact, an effect significant at the $10 \%$ level on the interaction term shows up when the number of deaths variable is considered (columns 4 to 6 , table ??).

Table 4 sums-up the results of tables 2 and 3 into one synthetic table. Here, the results concerning two of the disasters (Earthquakes and Floods) appear to be extremely robust from our tables 2 and 3, and can be summed up in the following manner: Earthquakes appear to have a robust negative effect on exports. Further, this impact appears to be homogenous across 
poor and non-poor countries, small and big ones. Floods affect exports of small countries in a robust manner and through the three alternatives variables of disasters at hand. Storms appear to affect exports of poor countries but less robustly as 2 out of the 3 alternatives variables of disasters produce negative and statistically significant estimators. For extreme temperatures, GeoMet data and EM-DAT are not consistent. While the former exhibit a negative impact, both for small or poor countries, the latter produces a non-significant one.

So far we have assumed that the intensity of disasters are affecting in a linear manner exports of victim countries. The effect might not be linear, however. One can imagine that for some typical natural disaster (say a flood or a storm), an event of remarkable intensity might affect infrastructure and alter employment of resources for a long period, while events that are not as remarkable might be recovered more easily during the year, allowing an easier catching up of exports. This is why we choose in what follows to examine whether this non-linearity can arise in the data. To do so, we define a variable that informs about whether the observed disaster ranks among the top $20 \%$ of the distribution of disasters of similar type for each year of observation. Two alternative indicators are considered here: a human damage based indicator computed out of EM-DAT data (i.e. number of persons killed); and a physical damage indicator computed out of GeoMet (i.e intensity of meteorological and geophysical measures of events). We compute these two measures for each of the four categories of disasters for all countries and all years, and call the obtained indicator, "extreme disasters" or "in Top $20 \%$ disaster" from either EM-DAT or GeoMet.

Table 5 concentrates on the results for EM-DAT, using human damage data. As it appears from the table, extreme disasters (that is, the Top $20 \%$ in terms of human losses) have a statistically significant and negative impact for 3 out of 4 families (Flood, Storms, and Earthquakes) but only when countries are of small size (i.e in the case of Flood and Earthcaques) or when the countries are poor (i.e. respectively, Storms). In the case of high changes in temperatures however, the signs reverses and becomes, for some reason, positive and statistically significant.

Table 6 turns to the results obtained using the Top 20\% of events based on physical damage data (GeoMet). Interestingly, most of the above results based on human damage (EM-DAT data) hold in the case of GeoMet too despite some exceptions. Table 7 sums-up the results of the two tables 5 and 6 . Several results can be highlighted:

- In the case of Earthquakes, the Top $20 \%$ of the disasters in terms of losses seem to harm exports probably as much as less remarkable ones. EM-DAT suggests the effect is more negative in the case of small countries but this result does not resist the data provided by GeoMet.

- Extreme floods appear to hit exports of typically small countries; 


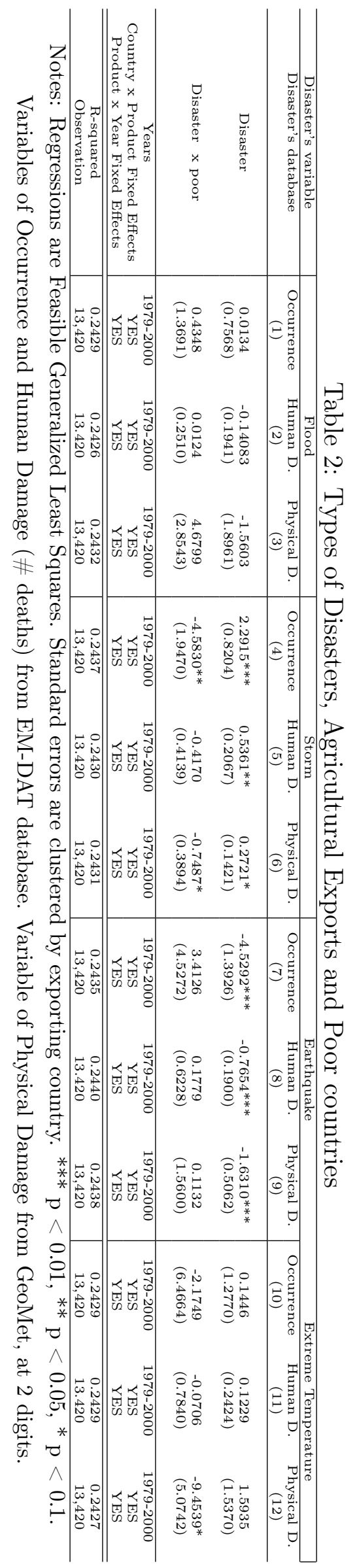




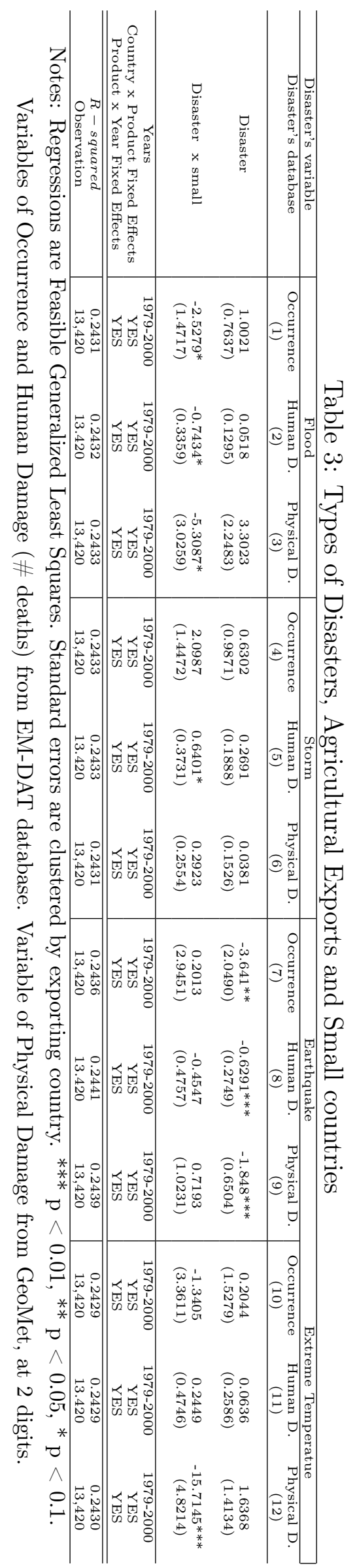




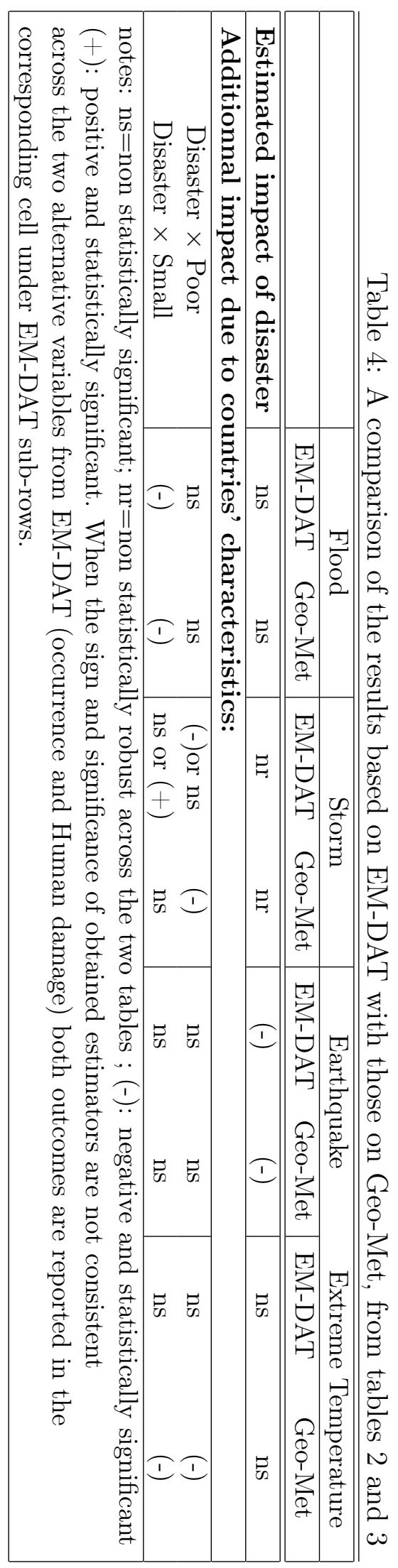


- Extreme storms affect exports of typically poor countries;

- Top $20 \%$ extreme changes in temperatures seem to be affecting exports in the GeoMet database and more so when the country is relatively small. But this outcome is not consistent with that from EM-DAT, where the observation of very harmful disasters of the same type appears to complicate the interpretation of the positive and statistically significant estimator being obtained;

- Finally, from a systematic comparison between the results of the two databases one can add-up another finding: almost all of the results obtained using physical damage data (GeoMet) are either associated with a non significant effect or a statistically negative and significant effect. One cannot claim a similar pattern for EM-DAT outcomes.

A closer look at the results synthetized by tables 4 and 7 enables to infer that floods in small countries do play a role in affecting exports but they are probably more likely to do so when floods are of extreme strength. The same argument can be applied for storms that take place in poor countries where the Top $20 \%$ seem to be most likely to be driving the results that have been found in table 4 .

How can one interprete these results in terms of magnitude? From here one needs to choose which specification is the most suitable to do the exercise. As already mentioned, one can either use the estimators from EM-DAT or those from GeoMet, although we think the results from GeoMet are probably more in line with our theoretical expectations (i.e. showing mostly either negative or non significant effects on trade). We thus choose to show magnitudes based on estimators from GeoMet related specifications.

Because extreme disasters seem apparently to be behind the negative effects that are estimated for storms and floods and because earthquakes estimators on the disaster variable do not change across the different tables when the occurrence variable is considered, we stick to table 6 to compute magnitudes after the occurrence of a given disaster. Let us consider first the impact of earthquakes. Here, the elasticity is obtained quasi immediately: when an earthquake occurs, the switch from 0 to 1 of the occurrence variable affects $\ln (1+$ occurrence $)$ by $\ln (1+1)-\ln (1+0)$ $=\ln (2)=0.69$. So the $\beta$ in equation (1) that equals -4.4 in table 6 for earthcaques, should be multiplied by 0.69 in order to estimate the impact on exports; that is $-4.4^{*} 0.69=-3.03$. Hence, agricultural exports would be reduced by a bit more than $3 \%$ after an earthquake, whichever the size of the country and its level of development.

Let us turn now to the impact of a storm. As already discussed earlier, it is most probable that only very remarkable storms would curb export flows. An occurrence of a very severe storm in a small country would then curb agricultural exports by $7.8 \%(=-11.33 \times 0.69)$, which is more than twice as much as an earthquake if the latter takes place in the same country. Finally, 


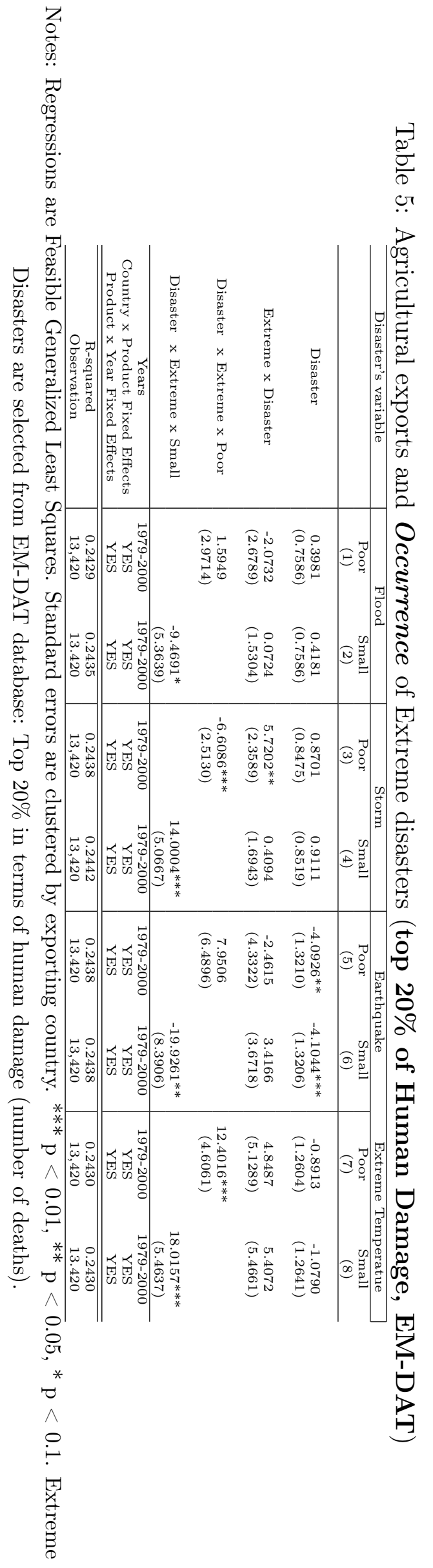




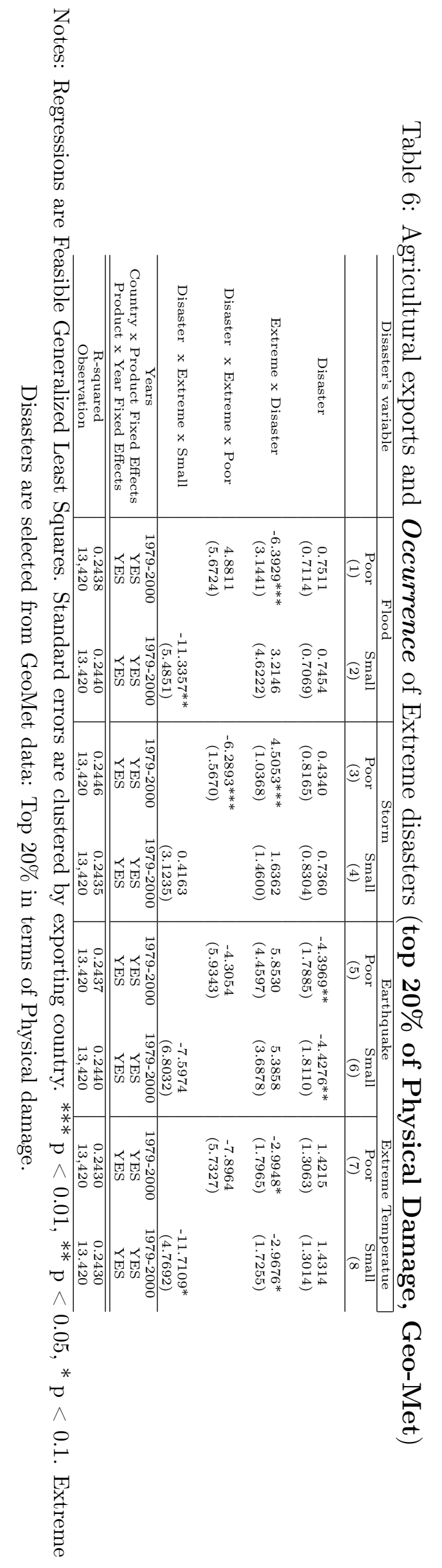




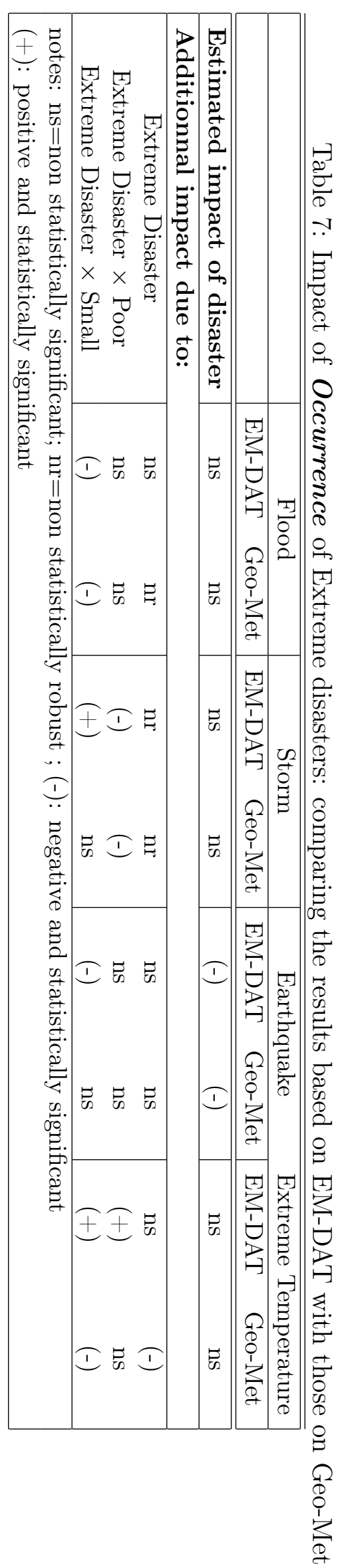


for the flood impact, notice first that the estimator on the interaction term (Extreme Disaster) $\times$ poor is a deviation from that on (Extreme Disaster) dummy, which happens to be positive and statistically significant (see column 3, table 6). Thus, one has to compute first the impact in absolute value (not in deviations) of an extreme flood in poor countries which is actually equal to $-6.28+4.5=-1.78$. One then obtains that a very severe flood in a poor country would reduce exports of agricultural products by $1.22 \%$ (i.e.- $1.78^{*} 0.69$ ), which happens to be of a small magnitude compared to say, earthquakes.

\section{Conclusion}

In this paper, we have focused on the impact of disasters on trade through the supply of resources channel. More precisely we have investigated the impact of disasters on total exports when driven by a reduction of its resource capacities. We have used two different databases EM-DAT and GeMmet and found consistent results on agricultural exports of hit countries:

- a clear negative impact for earthquakes, whatever the characteristics of hit countries are,

- a negative effect for storms on poor countries exports, but mainly when storms are of very high intensity,

- a negative impact of floods on small countries export flows, but arising quite likely when floods are very severe,

- an ambiguous effect for extreme temperatures.

Most of these results appear to be robust to the use of both types of datasets, EM-DAT and GeoMet, except for extreme temperatures events where GeoMet appears then to be more informative.

Although this paper proposes new results to the literature, one still can find that the expected negative impact of disasters does not show up systematically in our data. Two reasons might explain the absence of negative impact of disasters on trade of hit countries (supply effect):

a. Despite an analysis of small and poor countries and extreme events, the statistics remain highly aggregated. It makes sense to focus on natural disasters during rainfall season and to use more detailed data;

b. Economic mechanisms at work after a natural disaster remain mainly unknown; there could be other effects at play compensating the supply effect.

These ideas are the subject of future research in a companion paper. 


\section{Acknowledgements}

We would like to thank funding from Region Centre-Val de Loire (MUTMONDE project). We also thank participants to the 5th Thematic Workshop of the FAERE in Rennes, to the 16th RIEF doctoral meeting in Florence, and to ETSG 2016 in Helsinki for their precious comments. Usual disclimers apply. 


\section{References}

CRED (2016), "Annual Disaster Statistical Review 2015", Center for Research on the Epidemiology of Disasters, Université Catholique de Louvain.

Dell M., Jones B.F. and Olken B.A. (2014), "What Do We Learn from the Weather? The New Climate-Economy Literature", Journal of Economic Literature, 52(3), 740-798.

Felbermayr G. and Gröschl J. (2014), "Naturally negative: The growth effect of natural disaster", Journal of Development Economics, vol. 111, 92-106.

Gassebner, M., Keck A. and Teh R. (2010), "Shaken, Not Stirred: The Impact of Disasters on International Trade", Review of International Economics, 18(2), 351-368.

Guha-Sapir D., Below R. and Hoyois P. (2011) EM-DAT: International Disaster Database, www.emdat.be, Catholic University of Louvain, Brussels, Belgium.

Jones B.F. and Olken B.A. (2010), "Climate Shocks and Exports", The American Economic Review: Papers and Proceedings 100, May, 454-459.

Noy I. (2009), "The Macroeconomic Consequences of Disasters", Journal of Development Economics, 88, 221-231.

Oh C.H. and Reuveny R. (2010), "Climatic Natural Disasters, Political Risk, and International Trade", Global Environmental Change, 20, 243-254.

Toya H. and Skidmore M. (2007), "Economic development and the impacts of natural disasters", Economics Letters, 94, 20-25. 